\title{
Bases normativas e condições político-institucionais da gestão democrática em sistemas municipais de ensino do estado do Piauí
}

\author{
Raimunda Maria da Cunha Ribeiro ${ }^{a}$ \\ Elton Luiz Nardi b
}

\section{Resumo}

O trabalho tem por objetivo analisar o quadro normativo e as condições políticoinstitucionais relativos à gestão democrática do ensino público no âmbito dos sistemas municipais de ensino do estado do Piauí. Resultante da etapa estadual de uma pesquisa em rede de abrangência nacional, a delimitação empírica compreendeu os municípios piauienses com sistemas de ensino institucionalizados, tendo sido operado o exame das respectivas leis municipais. Os resultados evidenciam que a maior parte dos municípios não conta com sistema de ensino e que, entre os que o institucionalizaram, o quadro geral de princípios e espaços e mecanismos de participação é díspar e pouco sintonizado, havendo diferenças acentuadas entre as mesorregiões do estado. Conclui estar em causa a disposição para fazer avançar as condições de reforço à participação direta e ativa do cidadão na política e gestão da educação pública.

Palavras-chave: Sistemas municipais de ensino. Gestão democrática. Educação pública.

\section{Introdução}

A Constituição Federal de 1988 (BRASIL, 1988), em seu artigo 206, firmou o princípio da gestão democrática do ensino público como orientador de uma nova forma de administração educacional, inserindo a sociedade civil "não mais como coadjuvante do processo de formação histórico-política do país, mas como protagonista, importando, necessariamente, o princípio de participação" (NOGUEIRA; RANGEL, 2011, p. 518).

\footnotetext{
a Universidade Estadual do Piauí - Uespi. Corrente, Piauí, Brasil.

b Universidade do Oeste de Santa Catarina - Unoesc. Joaçaba, Santa Catarina, Brasil.

Recebido em: 27 jul. 2016

Aceito em: 20 mar. 2017
} 
Em paralelo, na linha da ascensão do município à condição de ente da federação e na perspectiva da descentralização federativa, a Carta pôs em marcha a implantação dos sistemas municipais de ensino, aos quais foi conferida, segundo o disposto no artigo 14 da Lei ${ }^{\circ}$ 9.394, de 20 de dezembro de 1996 (BRASIL, 1996), a atribuição de definir normas de gestão democrática para a educação básica, de acordo com suas peculiaridades. Mais recentemente, essa atribuição foi sublinhada pela Lei ${ }^{\circ} 13.005$, de 25 de junho de 2014 (BRASIL, 2014), que aprova o Plano Nacional de Educação (PNE) 2014-2024, com a fixação do prazo de dois anos, contados da publicação da lei, para que os estados, o Distrito Federal e os municípios disciplinassem a gestão democrática no âmbito de seus respectivos sistemas de ensino.

Tendo em vista esse contexto e a demanda por iniciativas dos municípios brasileiros na definição de referenciais de gestão para a educação pública, o presente trabalho tem por objetivo analisar o quadro normativo e as condições político-institucionais relativos à gestão democrática do ensino público no âmbito dos sistemas municipais de ensino do estado do Piauí.

A investigação da qual resulta este trabalho ${ }^{1}$ constitui parte da etapa estadual de uma pesquisa em rede que focaliza a implementação da gestão democrática do ensino público no âmbito dos sistemas municipais de ensino, e que conta com a participação de pesquisadores de instituições de ensino superior de outros sete estados brasileiros ${ }^{2}$.

A delimitação empírica da investigação compreende, portanto, os municípios piauienses com sistemas de ensino institucionalizados, cuja formalização tenha ocorrido entre a promulgação da atual Lei de Diretrizes e Bases da Educação Nacional (LDB) e o mês de junho de 2016, tendo sido operado o exame das respectivas leis municipais destinadas à organização dos sistemas de ensino.

Assim, na primeira parte do trabalho, são tecidas reflexões acerca da democratização da gestão educacional e os referidos desafios interpostos à materialização dessa opção política na atualidade, ainda que sob o imperativo do princípio constitucional da gestão democrática do ensino público. Situamos, nessa direção, a figura do município enquanto ente federativo, também encarregado de estabelecer normas complementares à gestão democrática no âmbito do seu sistema de ensino, além de apontar encaminhamentos adotados no estado do Piauí a fim de dar cumprimento a tal incumbência.

Pesquisa financiada pela Coordenação de Aperfeiçoamento de Pessoal de Nível Superior (Capes).

2 Santa Catarina, Rio Grande do Sul, Paraná, Rio de Janeiro, Maranhão, Ceará e Tocantins. 
A segunda parte do trabalho focaliza, mais especificamente, elementos constituintes do quadro normativo da gestão democrática do ensino público nos sistemas de ensino investigados, enfocados os princípios de gestão democrática e os espaços e mecanismos institucionalizados de participação firmados na legislação pesquisada. Com a sistematização e análise do conteúdo dos documentos examinados, tendo como referências contribuições de Bardin (2010), Bauer (2002) e Bogdan e Biklen (1994), são apresentados os resultados em nível mesorregional e em nível estadual. Por fim, na última seção, são tecidas algumas considerações provisórias sobre o tema investigado, indicativas de questões que se abrem e, portanto, suscitam novas análises.

\section{Democratização da gestão educacional: algumas notas}

A gestão democrática segue na arena do debate educacional brasileiro, tendo sido impulsionada a partir da segunda metade do século XX, ainda no curso das reações da sociedade brasileira às injunções da Ditadura Militar, que marcaram indelevelmente o país. Não há dúvida de que os movimentos pela redemocratização do país, aqui incluída a construção da Constituição Federal de 1988 e de uma nova LDB, constituíram uma etapa central da luta pela democracia no Brasil, ainda que a aprovação da lei da educação nacional tenha ocorrido oito anos depois, em outro contexto político.

Importa assinalar, contudo, que a democracia é um conceito histórico e politicamente construído, daí o fato de ser dinâmico e polissêmico. É nessa direção que Coutinho (2002) argumenta que não necessariamente os que se declaram democratas acreditam na democracia, até porque corre entre nós uma visão um tanto generalizada de que a democracia é uma virtude, tornando menos explícito o fato de que, com frequência, seu significado distancia-se daquele atribuído na história da humanidade e pelo pensamento político.

Podemos dizer que, no Brasil, a democracia é um fenômeno político relativamente recente, seguindo atravessado por desafios que se renovam e se modernizam, produzindo obstáculos à construção de uma democracia social. Para Frigotto (2002), nossa história é demarcada pelo sentido fraco de democracia, ou seja, uma democracia formal, pelo alto e mutilada de seu sentido mais profundo, pois "a democracia efetiva só pode ser construída sob a igualdade de condições socioeconômicas, culturais, educativas, etc. dos seres humanos na produção da sua vida individual e social" (p. 53). A força do poder, o influxo neoliberal e as reformas economicistas, de um lado, e as lutas travadas a partir da participação popular, de outro, estampam que, por aqui, a democracia segue sendo um campo de profundas contradições, tencionados referenciais de dignidade humana e do exercício da cidadania, como a qualidade da participação política dos atores sociais. 
Na linha das análises de Díaz Bordenave (1985), referimo-nos à participação enquanto via de aperfeiçoamento das condições de democratização e de construção da consciência crítica e política, expressa no envolvimento das pessoas na construção da realidade político-social. Trata-se, nesse sentido, da participação que implica a ação política dos atores sociais em processos decisórios acerca dos assuntos de interesse público e de problemas e demandas coletivos, da identificação ao acompanhamento, controle, fiscalização e avaliação (LIMA, 2003).

A Constituição Federal de 1988 consagrou a participação cidadã como categoria central, ordenamento jurídico de caráter democrático que deve orientar o Estado em termos de gestão pública (BRASIL, 1988, art. 37). É com lastro nessa categoria que o artigo 206 da Carta afirma o princípio da gestão democrática do ensino público, como também o faz a atual $\mathrm{LDB}^{3}$, lançando aposta na ideia de uma sociedade participativa, naquela em que os cidadãos têm parte na produção e usufruto dos bens de maneira equitativa (DÍAZ BORDENAVE, 1985).

Conforme referido, a mesma Constituição elevou o município à condição de ente federado, resultante de uma reorganização jurídica do chamado pacto federativo. Estabeleceu, pois, a competência privativa da União para legislar sobre "[...] diretrizes e bases da educação nacional" (BRASIL, 1988, artigo 22), e a competência comum da União, dos estados, do Distrito Federal e dos municípios de "[...] proporcionar os meios de acesso à cultura, à educação e à ciência” (BRASIL, 1988, artigo 23).

Assim, decorrente do novo pacto federativo, o município teve seu campo de ação ampliado, obtendo um grau de autonomia até então inédito na história do Brasil (FARIA; SOUZA, 2004). Sua ascensão à condição de ente da federação, como entidade com autonomia política, administrativa e financeira, com capacidade de auto-organização, também lhe rendeu autonomia no campo educacional, com o direito de organização do sistema de ensino próprio, instância com base constitucional, consequente ao caráter de pessoa jurídico-política de direito interno e com autonomia. Com a criação legal de seus órgãos normativo e executivo, além do que dispõem os artigos 11 e 18 da LDB, o município passa a imprimir sua forma própria de entidade política autônoma (BRASIL, 2000), tornando o sistema municipal de ensino uma "forma peculiar de as forças sociais locais interpretarem e inscreverem-se na educação brasileira, explicitando traços característicos e de identidade próprios" (WERLE; THUM; ANDRADE, 2009, p. 401).

Conforme anotam Nogueira e Rangel (2011, p. 518), "mesmo que legalmente a gestão democrática não atinja o setor privado, o caráter ético e axiológico da democracia paira sobre todas as instituições escolares ao repudiar todas as formas de autoritarismo". 
Com essa configuração, as incumbências dos municípios passaram a compreender, basicamente, dois agrupamentos: as que pressupõem instituição do sistema próprio em seu modus operandi; e as que independem dessa instituição, caso a opção seja pela integração ao sistema estadual de ensino ou a composição, com ele, de um sistema único de educação básica. É nesse contexto que os sistemas municipais de ensino também foram incumbidos de definir as normas da gestão democrática do ensino público, conforme estabelece o artigo 14 da LDB, sendo devida a associação da gestão democrática das escolas públicas a critérios de mérito e desempenho e à consulta pública da comunidade escolar, conforme fixou o PNE 2014-2024, por meio da meta 19 (BRASIL, 2014).

Atentos a essa incumbência e ao modelo de descentralização, prevalecente desde os anos de 1990 como possibilidade de Estado mínimo e mercado máximo, modelo esse situado em um contexto pouco favorável à democracia participativa e uma perspectiva sociocomunitária de desenvolvimento, Souza e Castro (2012) problematizam a dicotomia entre a difusão do ideário democrático no âmbito dos sistemas municipais de ensino e a sua concretização no campo das políticas públicas locais. Ao destacarem o fato de a gestão democrática não ser necessariamente lastreada pelo debate crítico, referem situações como a associação direta entre descentralização, democracia e participação social, como se houvesse sempre uma mútua e imediata dependência entre elas.

$\mathrm{Na}$ análise de Paz (2015), que toma por base os resultados de estudo acerca de uma experiência municipal paraense, embora o ato da criação do sistema municipal de ensino e o aparato legal que lhe dá sustentação não constituam, por si só, garantia de instalação e ampliação de processos conducentes a políticas de democratização da gestão do ensino púbico em nível local, tais medidas e a dinâmica objetivada por elas podem significar um importante passo rumo a essa direção. Entretanto, quando deslocadas as lentes para o cotidiano desses sistemas próprios de ensino, os desafios da democratização são alargados ou, ao menos, tornam-se mais evidentes. É o que sugerem Flach e Sakata (2016), em estudo sobre a experiência de um sistema municipal de ensino do Paraná, ao concluírem que a almejada participação popular na gestão pública da educação segue tutelada por interesses governamentais, servindo, ainda, à legitimação de ações dos agentes públicos.

Essas são evidências de que, como âmbito de formulação e de implementação de políticas de educação e de organização do trabalho educativo, a gestão da educação é um processo guiado por determinadas opções políticas, constituídas a partir da dinâmica de relações que se desenvolvem nos contextos institucionais interno e 
externo. Assim, na perspectiva de um projeto de democratização, a participação política e a autonomia figuram como elementos de ponta para a consecução de uma proposta de descentralização do poder e, portanto, para um modelo de gestão da educação distinto do experimentado (OLIVEIRA et al., 2010).

Pensando assim, o que está em questão é, fundamentalmente, o exercício do poder decisório e a dinâmica dos processos que o assistem. Nesse sentido, em se tratando dos sistemas municipais de ensino, destacam-se as instâncias de participação no âmbito local e suas condições concretas de viabilizar legitimamente a descentralização no trato de assuntos educacionais de interesse público. Contudo, uma leitura da viabilização dessa perspectiva de descentralização, enquanto mecanismo de distribuição do poder, demanda que sejam considerados tempos e contextos determinados, posto que, no caso dos sistemas educacionais, não é possível fazer generalizações quanto aos seus desdobramentos (BUENO, 2004), inclusive porque é imperativo que se atente para diferenças existentes entre medidas puramente técnicas e objetivos fundamentalmente políticos (ROMÃO, 2010).

De todo modo, essa expectativa em termos de opção e de ação políticas, na opinião de Arroyo (2008), é indicativa de que as formas de administrar o sistema educacional não são mais as mesmas a partir da bandeira da gestão democrática. É indicativa, também, de que dela decorre certa complexificação das responsabilidades, pois a aposta na capacidade reflexiva dos sujeitos envolvidos, com vistas a um planejamento prospectivo de normas, estruturas, mecanismos e arranjos, deve corresponder às expectativas lançadas (CUNHA, 2014).

Importa assinalar também que, ainda na década de 1980, estados e municípios encetaram políticas educacionais endereçadas à redemocratização da escola pública, dentre as quais experiências de escolha de diretores como forma alternativa à nomeação vertical motivada por interesses político-partidários. Em Teresina, por exemplo, a Secretaria Municipal de Educação regulamentou, em 1984, a nomeação de diretores para um período de dois anos, precedida da indicação de um colégio eleitoral composto pelos professores e especialistas em exercício, funcionários em atividade na escola, alunos com idade igual ou superior a 15 anos e responsáveis pelos alunos menores de 15 anos (TERESINA, 1984, artigo $1^{\circ}$ ). Tratava-se da primeira referência de ação municipal destinada à gestão democrática, em nível de município, no estado do Piauí. Anterior à promulgação da atual Constituição Federal, a experiência já se alinhava, em certa medida, ao movimento pelo reforço da autonomia municipal, ainda que o sistema municipal de ensino de Teresina tenha sido organizado somente no ano de 2000 , por meio da Lei ${ }^{\circ} 2.900$, de 14 de abril (TERESINA, 2000). 
Por seu tempo, a Lei Estadual n ${ }^{\circ}$ 5.101, de 23 de novembro de 1999 (PIAUÍ, 1999), na direção do previsto na atual LDB, dispõe, em seu artigo $8^{\circ}$, sobre a organização dos sistemas de ensino e a constituição dos órgãos executivo (Secretaria Municipal de Educação) e normativo (Conselho Municipal de Educação) do sistema, definindo o procedimento a ser adotado pelo município a fim de confirmar sua opção pelo sistema de ensino próprio.

Basicamente, caberá ao município comunicar ao Conselho Estadual de Educação (CEE) a aprovação da lei de criação do sistema e da lei de criação do Conselho Municipal de Educação, embora seja comum que isso ocorra por meio de uma única lei. A comunicação ao CEE ocorre através de processo a ser aprovado em sessão plenária e homologado através de portaria do Conselho.

Consoante o Parecer CEE/PI n ${ }^{\circ}$ 54, de 03 de dezembro de 2004 (PIAUÍ, 2004), o Conselho Estadual dá indicativos acerca do processo de implementação dos sistemas municipais e respectivos conselhos de educação. Os municípios, por sua vez, podem adotar uma das formas, como já definira a LDB: autônomo (criado por lei municipal); integrado (integrado à Secretaria Estadual de Educação); sistema único (forma compartilhada, com o Estado, de uma única rede de escolas dentro de um sistema único de educação).

Embora seja evidente a orientação para que sejam organizados os sistemas autônomos, o Parecer CNE/CEB n ${ }^{\circ}$ 30, de 12 de setembro de 2000, registra que "a base dos sistemas municipais de ensino é sua existência constitucional própria, autônoma e consequente ao caráter do município como pessoa jurídico-política de direito público interno com autonomia dentro de seu campo de atuação" (BRASIL, 2000, p. 12); conforme veremos adiante, a maioria dos municípios piauienses mantém os seus sistemas integrados ao sistema estadual.

\section{Princípios, espaços e mecanismos de participação: a gestão democrática nos sistemas municipais de ensino do Piauí}

Na década de 1940, a divisão do espaço geográfico do estado do Piauí, segundo suas homogeneidades naturais e econômicas, compreendia oito zonas fisiográficas, a saber: Alto Parnaíba, Planalto, Litoral, Sertão, Ibiapaba, Carnaubeira, Baixo Parnaíba e Médio Parnaíba. Com o passar do tempo, essa divisão foi ficando insuficiente, por não fornecer os dados necessários ao planejamento econômico do estado, razão pela qual outro modelo de divisão, denominado microrregião homogênea, foi implantado pelo Instituto Brasileiro de Geografia e Estatística 
(IBGE) na década de 1970. Assim posto, o estado passou a ser dividido em 11 microrregiões: Baixo Parnaíba, Campo Maior, Teresina, Médio Parnaíba, Valença, Floriano, Baixões Agrícolas, Alto Parnaíba, Médio Gurgueia, Alto do Piauí e Canindé e Chapada do Extremo Sul.

Na década de 1990, a exemplo dos demais estados brasileiros, o Piauí recebeu nova divisão do seu espaço geográfico, em substituição à divisão por microrregiões homogêneas. O espaço geográfico piauiense foi dividido, então, em quatro mesorregiões, conforme ilustra o Mapa 1. É com base nessa divisão que o presente estudo enfoca a temática da institucionalização dos sistemas municipais de ensino e a normatização da gestão democrática do ensino público no âmbito desses sistemas.

Mapa 1. Mesorregiões geográficas do estado do Piauí.

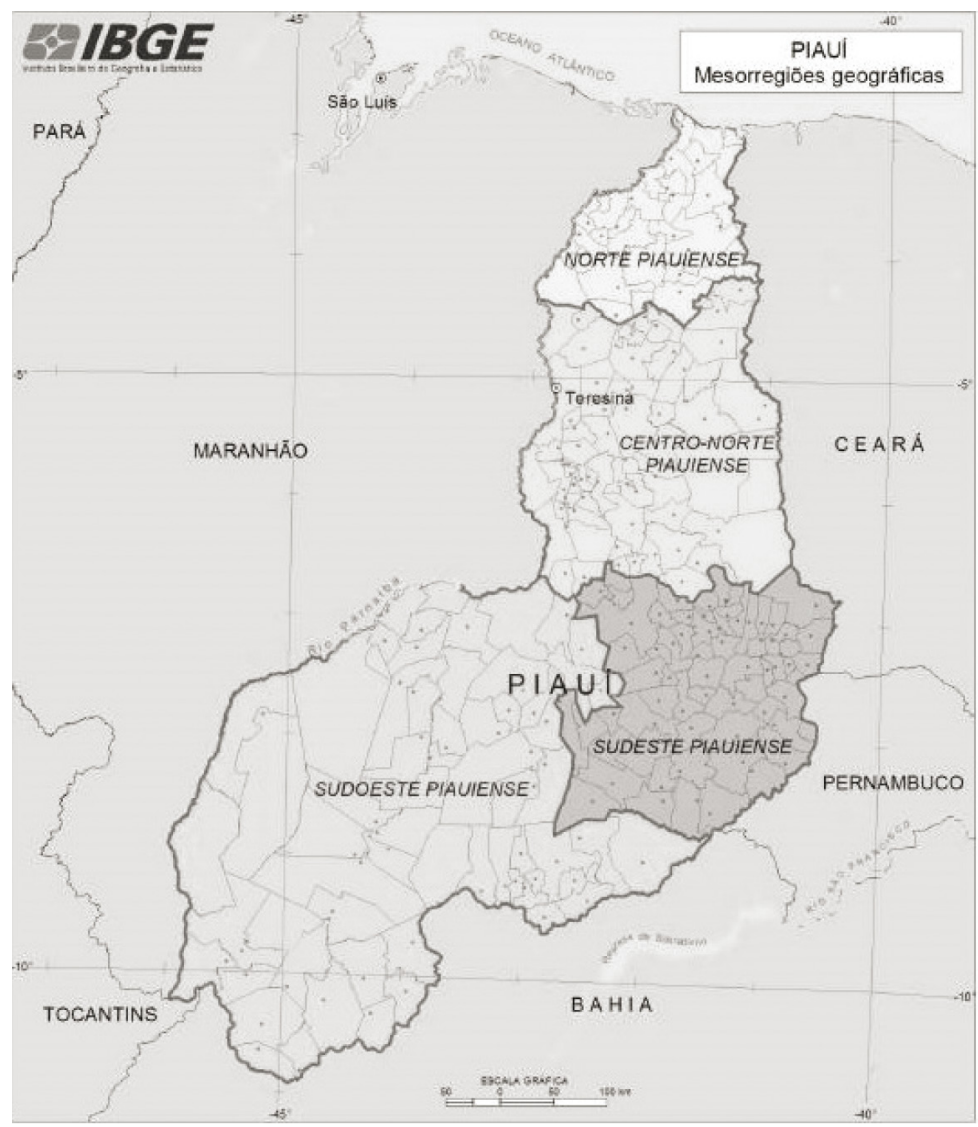

Fonte: Brasil (2011). 
De acordo com o levantamento de elementos gerais que caracterizam a institucionalização dos sistemas municipais de ensino no estado do Piauí, dos atuais 224 municípios distribuídos nas quatro mesorregiões geográficas, somente 87 contam com sistemas considerados autônomos pelo CEE/PI (PIAUÍ, 2004), conforme ilustra o Gráfico 1. Os demais continuam integrados ao sistema estadual de ensino, constituindo um cenário distinto de estados como Santa Catarina, onde 95\% dos municípios possuem sistemas próprios de ensino, e Paraná, que conta com apenas 15 sistemas institucionalizados em um universo de 399 municípios.

Mas o que informa esse cenário de institucionalização de sistemas municipais de ensino? A nosso ver, guardadas as especificidades que marcam a realidade nos diferentes estados brasileiros, esse cenário indicia que a organização dos sistemas municipais é, ainda, uma tarefa em processo no país, mesmo depois de 20 anos da vigência da atual LDB, posto ser implicada por fatores de diversas ordens.

Reforçam essa percepção estudos que focalizam peculiaridades da organização desses sistemas de ensino em diferentes contextos. Panis e Nardi (2014), por exemplo, em estudo sobre a implantação em municípios de uma região catarinense, assinalam a forte influência de fatores sociais, políticos, institucionais e culturais na decisão pela organização dos sistemas próprios de ensino, assim como nas condições de funcionamento desses sistemas.

Já Paz (2009), em pesquisa sobre a implantação de sistema de ensino em município paraense, destaca, principalmente, a opção política dos agentes políticos locais e, como ocorreu no caso estudado, na disposição de submeter à análise criteriosa os problemas educacionais locais. É nessa direção que Pereira (2010), também versando sobre uma experiência paraense de institucionalização de um sistema

Gráfico 1. Sistemas municipais de ensino institucionalizados no estado do Piauí - 2016*.

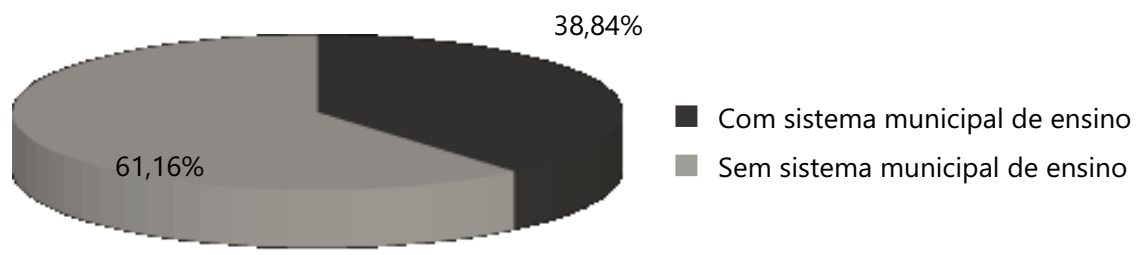

*Em 2016, até o mês de junho, não houve institucionalização de novos sistemas de ensino. Fonte: Legislação municipal e portarias do Conselho Estadual de Educação do Piauí (CEE/PI) (PIAUÍ, 2004). 
municipal de ensino, refere a necessidade de os agentes públicos disporem-se a abdicar de expedientes patrimonialistas arraigados na prática governamental.

Em suma, trata-se de uma organização um tanto complexa, pois diz respeito a um todo orgânico, um conjunto de forças sociais, políticas, culturais e econômicas, que envolve órgãos municipais (executivo e normativo), instituições de educação básica administradas pelo poder público municipal e instituições privadas de educação infantil.

No estado do Piauí, onde a institucionalização ainda se encontra em curso, as iniciativas foram inauguradas somente a partir do ano de 2000 , e, conforme ilustra o Gráfico 2, o processo tem sido irregular entre os municípios, ora com maior impulso, como ocorreu nos anos de 2006, 2007, 2009 e 2011, ora com menor mobilização, ou mesmo com nenhuma iniciativa, como ocorreu entre 1997 e 1999 e no ano de 2003.

Gráfico 2. Sistemas municipais de ensino institucionalizados a cada ano no estado do Piauí -2000 a $2016^{*}$.

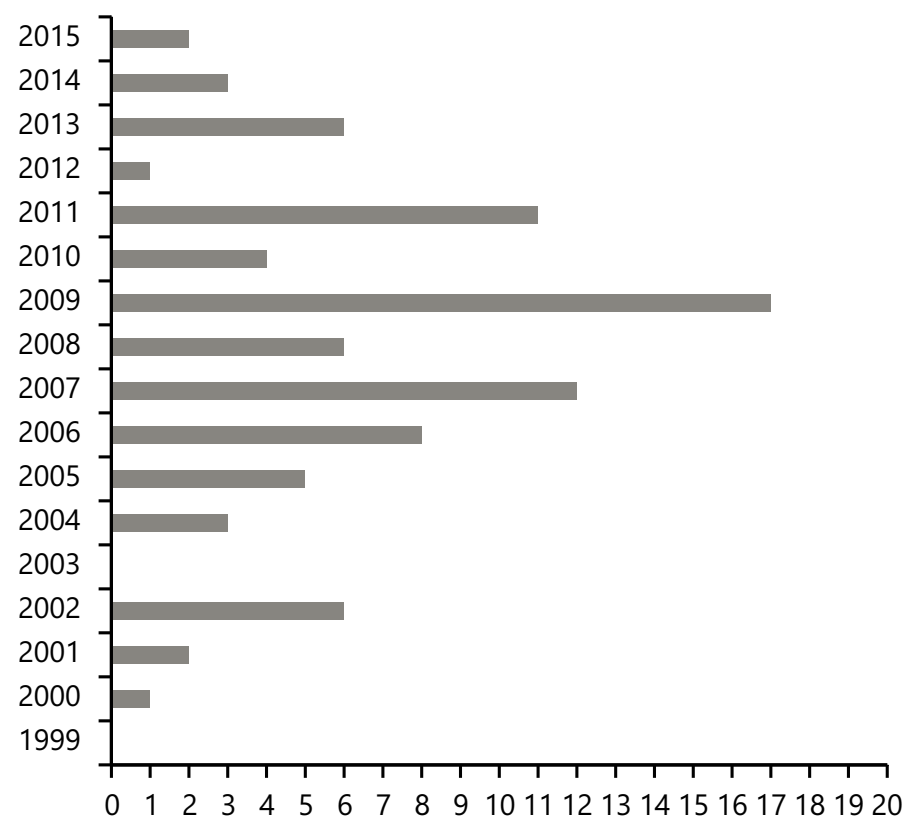

* Em 2016, até o mês de junho, não houve institucionalização de novos sistemas de ensino. Fonte: Rede Mapa (2016).

Aberta no ano de 2000, por iniciativa do município de Teresina, a institucionalização de sistemas municipais de ensino ficou restrita, até o ano de 2003, a apenas 
nove municípios do estado. Como se pode observar no Gráfico 2, o ano de 2004 inaugurou a fase principal do processo de organização dos sistemas, que se estendeu até o ano de 2011 e teve o ano de 2009 como o ponto alto dessa fase principal. Uma última fase pode ser creditada ao período entre 2013 a 2015, embora em um movimento decrescente, inversamente proporcional à fase inicial compreendida entre os anos de 2000 a 2002.

Esse movimento irregular e cada vez mais desacelerado nos leva a questionar sobre o que tem representado para os municípios a institucionalização de seus sistemas próprios de ensino. Do ponto de vista gestionário, estaríamos ante uma descentralização do poder decisório a repercutir na gestão participativa e, por extensão, na democratização social? Conforme indiciam estudos acerca de desafios e possibilidades associados à organização dos sistemas municipais de ensino, uma relação entre descentralização e democratização, firmada no pressuposto da partilha do poder decisório, pode conferir nova fisionomia à gestão da educação pública na esfera local. Nessa direção, Stürner (2011) ressalta a importância das comunidades escolares na busca pelo direito de decidir sobre os rumos da educação escolar que a serve, o que concorda com as conclusões de Pereira (2010), para quem o sistema municipal de ensino tem potencial para impulsionar a participação com vistas a uma gestão educacional pautada em interesses coletivos. Todavia, segundo esta autora, a materialização desse perfil constitui um desafio, haja vista implicar disputas de poder frequentemente referenciadas em projetos distintos de educação e de gestão pública do setor.

Em suma, conforme contribuem Sarmento (2005) e Teodoro (2001), se, por um lado, o sistema de educação escolar constitui um espaço de afirmação da cidadania, democratização social e também de luta e compromisso, por outro, é sabido que a opção pela organização de um sistema de ensino também implica disposição para corresponder a demandas político-administrativas decorrentes dessa opção e do papel esperado desse sistema de ensino, dentre os quais está o de promover a democratização da gestão educacional. Por isso, como um ato político e expressão da correlação de forças, tal institucionalização também informa um perfil de gestão - criativa e progressista ou reiterativa e conservadora (PARO, 1986) -, mesmo em nível normativo.

$\mathrm{Na}$ seara desse debate e de um ponto de vista mais otimista, Sarmento (2005) anota que "o município tem sido apontado como um campo potencializador de experiências democráticas, principalmente pela proximidade do governo local com os cidadãos" (p. 1373). Entretanto, também assinala que a adoção de políticas neoliberais, como a ocorrida a partir dos anos de 1990, "estimulou o repasse de 
responsabilidades para os municípios sem considerar suas reais condições de administração" (2005, p. 1373).

Esses fatores, a par da opção política pelo exercício autônomo nos assuntos educacionais e da influência de práticas políticas marcadas pelo clientelismo e corporativismo (AVELAR, 1996; IANNI, 2004), repercutirão na concretização dos sistemas municipais de ensino e, segundo nossa hipótese, podem justificar o quadro díspar da implantação desses sistemas nas diferentes mesorregiões do Piauí, conforme ilustra o Gráfico 3.

Os dados permitem perceber que, em duas mesorregiões (Sudeste e Sudoeste), o processo de institucionalização se deu, praticamente, na mesma dinâmica temporal do quadro geral do estado do Piauí, enquanto as demais mesorregiões demarcaram um movimento distinto, principalmente no caso da mesorregião

Gráfico 3. Sistemas Municipais de Ensino no estado do Piauí, segundo o ano de institucionalização e mesorregião geográfica - 2000 a 2016*.

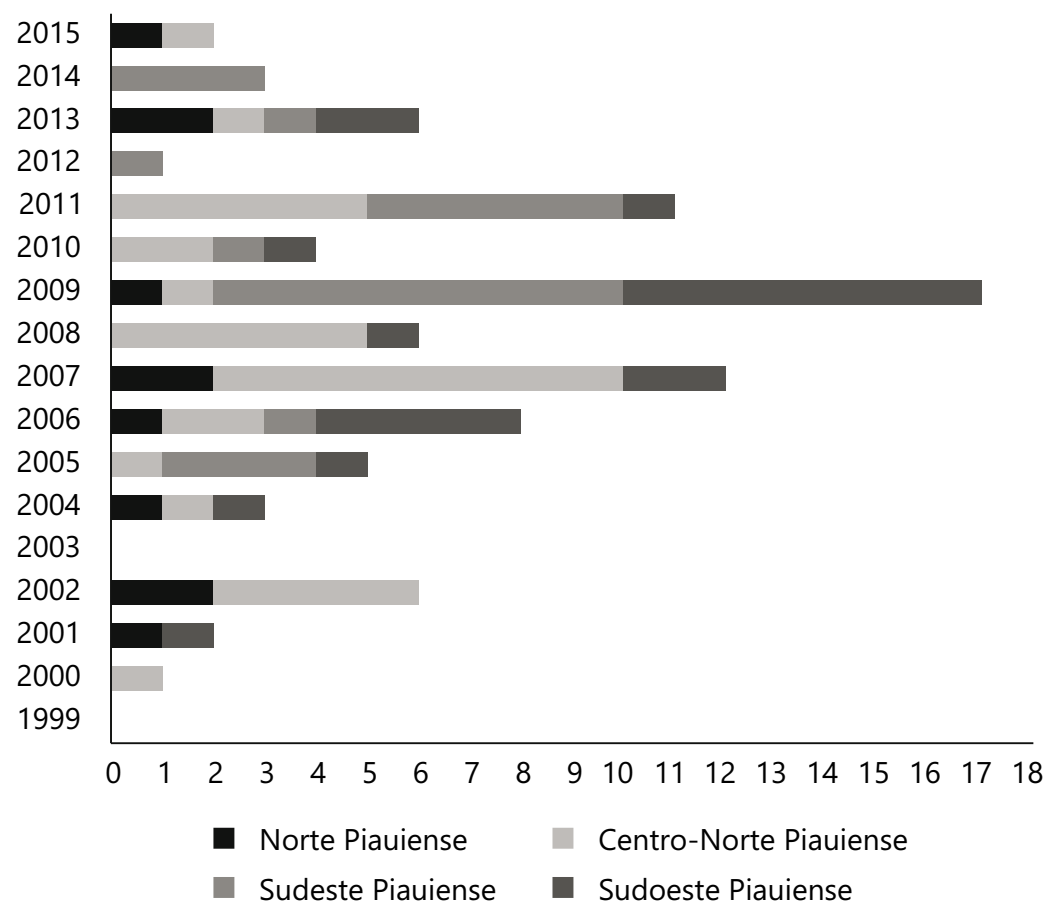

* Em 2016, até o mês de junho, não houve institucionalização de novos sistemas de ensino. Fonte: Rede Mapa (2016). 
Norte Piauiense. Nessa, composta por 32 municípios, a institucionalização dos sistemas iniciou somente no ano de 2001, tendo sido registrada a última medida no ano de 2013, sem que fosse identificado um ano ou período de destaque desse processo. Nesse período, 11 municípios formalizaram seus sistemas próprios, o que significa dizer que $65,6 \%$ do total da mesorregião seguem integrados ao sistema estadual de ensino do Piauí.

A mesorregião Centro-Norte Piauiense, que abrange a capital Teresina e os municípios mais próximos geograficamente, conta com 64 municípios, dos quais somente 32 institucionalizaram seus sistemas. É possível que a localização geográfica e, portanto, a proximidade de órgãos, como o Conselho Estadual de Educação, tenha contribuído para o maior percentual de municípios com sistemas de ensino próprios. Vale assinalar que, nessa mesorregião, o processo de implantação dos sistemas iniciou-se no ano de 2000, com o município de Teresina ${ }^{4}$, e que, a exemplo das demais mesorregiões, o movimento de institucionalização também ocorreu de forma irregular, embora seja possível verificar um impulso no ano de 2007, seguido dos anos de 2008 e 2011.

No caso da mesorregião Sudeste Piauiense, da qual fazem parte 66 municípios, os dados evidenciam a implantação de 23 sistemas de ensino no período. Ou seja, $43 \%$ dos municípios da mesorregião seguem integrados ao sistema estadual. $\mathrm{Na}$ comparação com as demais mesorregiões, a Sudeste Piauiense tardou mais a iniciar a institucionalização de sistemas municipais, posto que a primeira experiência data do ano de 2005. Conforme ilustra o Gráfico 3, o ano de 2009 registrou o maior impulso na implantação desses sistemas, o que ocorreu novamente no ano de 2011 embora com menor intensidade.

Por fim, quanto à mesorregião Sudoeste Piauiense, que comporta 62 municípios, os dados dão conta de que 21 sistemas de ensino foram organizados até o mês de junho de 2016. Os demais 41 municípios seguem integrados ao sistema estadual de ensino. Com a primeira experiência datada de 2001, também nessa mesorregião houve um maior impulso na institucionalização dos sistemas municipais de ensino no ano de 2009.

E sobre a gestão democrática do ensino público, o que estabelecem as leis dos sistemas de ensino? A esse respeito, buscamos identificar e sistematizar elementos que informam princípios da gestão democrática e espaços e mecanismos institucionalizados de participação, verificando a frequência e o conteúdo em nível mesorregional e estadual.

\footnotetext{
${ }^{4}$ Todavia, a lei que institucionaliza o sistema municipal de ensino de Teresina não dispõe, em específico, sobre a gestão democrática do ensino público.
} 
Conforme referido, 87 municípios piauienses contam com sistema de ensino institucionalizado, contudo, em 33 deles, as respectivas leis de institucionalização não tratam do tema da gestão democrática do ensino público em específico. Esse mesmo retrato, segundo as mesorregiões do estado, consta do Gráfico 4, sendo possível verificar que, em duas delas, o número de leis sem dispositivos sobre o tema supera ou praticamente se equipara ao das que o contemplam.

Identificada a recorrência do tema no conjunto de leis, verifiquemos agora o conteúdo dos dispositivos constantes nos documentos municipais, iniciando pelos princípios da gestão democrática do ensino público. Tal conteúdo está sintetizado no Quadro 1.

De acordo com os dados do Quadro 1, é possível verificar que a participação, embora mencionada diretamente em sete dos 14 princípios levantados e compreendida indiretamente nos demais, sobressai na elaboração e atualização dos planos municipais de educação. É possível verificar, ainda, que a maior parte das leis examinadas não traz, como princípio da gestão democrática,

Gráfico 4. Número de leis de institucionalização de sistemas municipais de ensino do Piauí com e sem dispositivos sobre gestão democrática do ensino público, segundo as mesorregiões geográficas - 2000 a $2016^{*}$.

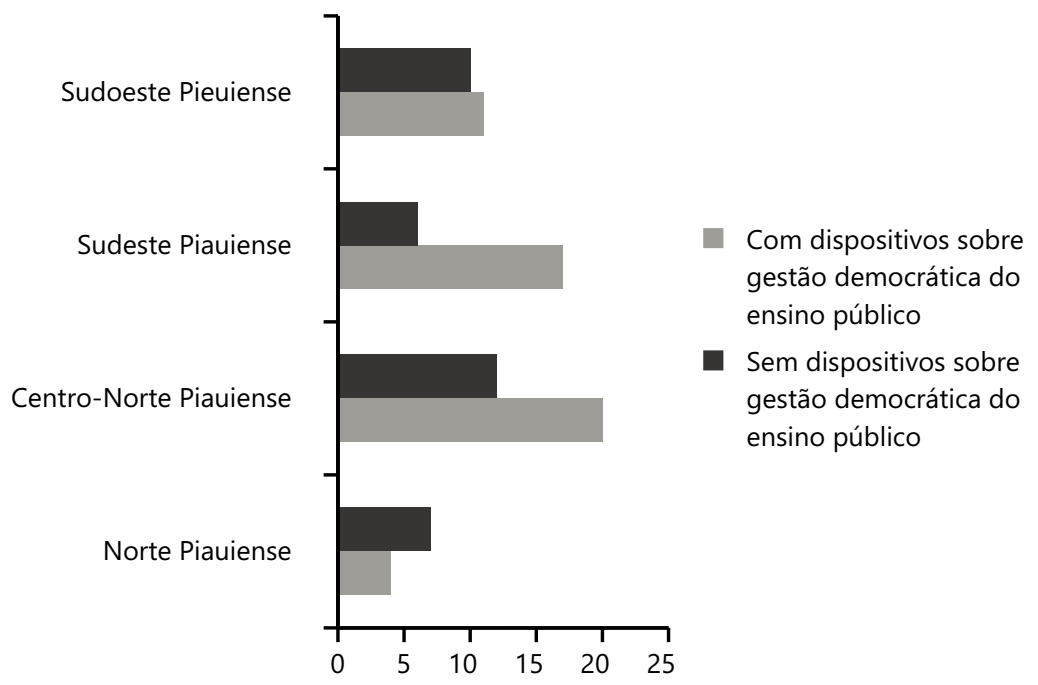

* Em 2016, até o mês de junho, não houve institucionalização de novos sistemas de ensino.

Fonte: Rede Mapa (2016). 
Quadro 1. Síntese dos princípios da gestão democrática do ensino público constantes nas leis dos sistemas municipais de ensino do estado do Piauí, segundo as mesorregiões geográficas.

\begin{tabular}{|c|c|c|c|c|c|}
\hline \multirow[b]{2}{*}{ Princípios } & \multicolumn{5}{|c|}{ Frequência } \\
\hline & $\begin{array}{c}\text { Norte } \\
\text { Piauiense } \\
\text { (11 leis) }\end{array}$ & \begin{tabular}{|c|} 
Centro- \\
Norte \\
Piauiense \\
(32 leis)
\end{tabular} & \begin{tabular}{|c|} 
Sudeste \\
Piauiense \\
(23 leis)
\end{tabular} & \begin{tabular}{|c|} 
Sudoeste \\
Piauiense \\
(21 leis)
\end{tabular} & $\begin{array}{c}\text { Total } \\
\text { (87 leis) }\end{array}$ \\
\hline $\begin{array}{l}\text { Participação na elaboração e } \\
\text { atualização do Plano Municipal de } \\
\text { Educação }\end{array}$ & 8 & 22 & 17 & 16 & 63 (72,4\%) \\
\hline $\begin{array}{l}\text { Participação dos profissionais da } \\
\text { educação, pais e responsáveis na } \\
\text { elaboração do projeto político- } \\
\text { pedagógico }\end{array}$ & 7 & 15 & 9 & 5 & $36(41,4 \%)$ \\
\hline $\begin{array}{l}\text { Conferência Municipal de Educação } \\
\text { como fórum máximo de deliberação }\end{array}$ & 2 & 11 & 14 & 7 & $34(39,1 \%)$ \\
\hline $\begin{array}{l}\text { Eleição direta para o } \\
\text { Conselho Escolar }\end{array}$ & 2 & 10 & 15 & 6 & 33 (37,9\%) \\
\hline $\begin{array}{l}\text { Autonomia das escolas na gestão } \\
\text { pedagógica, administrativa e } \\
\text { financeira }\end{array}$ & 4 & 12 & 9 & 7 & 32 (36,8\%) \\
\hline $\begin{array}{l}\text { Participação da comunidade, dos } \\
\text { conselhos e da sociedade civil }\end{array}$ & 1 & 10 & 9 & 10 & $30(34,5 \%)$ \\
\hline $\begin{array}{l}\text { Participação na elaboração do } \\
\text { Plano Plurianual de Educação }\end{array}$ & 2 & 9 & 8 & 5 & $24(27,5 \%)$ \\
\hline $\begin{array}{l}\text { Participação na elaboração } \\
\text { do Orçamento Municipal da } \\
\text { Educação e na Lei de Diretrizes } \\
\text { Orçamentárias }\end{array}$ & 2 & 9 & 8 & 3 & $22(25,3 \%)$ \\
\hline $\begin{array}{l}\text { Participação da comunidade } \\
\text { escolar e local em órgãos } \\
\text { colegiados }\end{array}$ & 6 & 7 & 9 & - & $22(25,3 \%)$ \\
\hline $\begin{array}{l}\text { Realização de eleição direta para a } \\
\text { direção de escolas }\end{array}$ & 1 & 5 & 7 & 5 & $18(20,6 \%)$ \\
\hline $\begin{array}{l}\text { Transparência nos procedimentos } \\
\text { pedagógicos, administrativos e } \\
\text { financeiros }\end{array}$ & 4 & 3 & 1 & 4 & 11 (12,7\%) \\
\hline $\begin{array}{l}\text { Participação na elaboração e } \\
\text { atualização no Plano de Carreira, } \\
\text { Cargos e Salários }\end{array}$ & - & 8 & 1 & 2 & 11 (12,7\%) \\
\hline $\begin{array}{l}\text { Descentralização das decisões } \\
\text { sobre o processo educacional }\end{array}$ & 3 & 2 & 1 & 4 & $10(11,5 \%)$ \\
\hline $\begin{array}{l}\text { Liberdade de organização dos } \\
\text { segmentos da comunidade escolar }\end{array}$ & 3 & 2 & 1 & 4 & $9(10,3 \%)$ \\
\hline
\end{tabular}

Fonte: Rede Mapa (2016). 
a participação dos profissionais da educação na elaboração do projeto pedagógico da escola, assim como o da participação da comunidade escolar e local em conselhos escolares ou equivalentes, haja vista figurarem, respectivamente, em apenas $41,4 \%$ e $25,3 \%$ dos documentos ${ }^{5}$. Vale observar que esses princípios são apontados no artigo 14 da LDB e, portanto, devem figurar no conjunto fixado em âmbito municipal.

Outra constatação oportunizada pelos dados é que, em cada mesorregião, a proporção de menções desses dois princípios em relação ao número de leis é muito distinta. O que dispõe sobre a participação dos profissionais da educação, pais e responsáveis na elaboração do projeto político-pedagógico figura em apenas nove das 23 leis municipais do Sudoeste Piauiense, enquanto, nos sistemas de ensino da mesorregião Norte Piauiense, o princípio consta em sete das 11 leis municipais examinadas. Já em relação à participação da comunidade escolar e local em órgãos colegiados, os dados permitem destacar tanto a mesorregião Sudoeste Piauiense, pela ausência desse princípio nas leis examinadas, quanto a Norte Piauiense, que registra a maior proporção (seis menções para 11 leis).

Fogem a essa característica apenas dois princípios levantados, cuja incidência em cada mesorregião, proporcionalmente ao respectivo número de leis, revela-se mais equilibrada. Trata-se do princípio "participação na elaboração e atualização do Plano Municipal de Educação", presente em cerca de dois terços do conjunto de leis de cada mesorregião, e do princípio "autonomia das escolas na gestão pedagógica, administrativa e financeira", constante em cerca de um terço dos documentos de cada uma das quatro mesorregiões.

No tocante à diversidade e aos enfoques dos princípios levantados, entendemos que tanto podem sugerir certa observância a peculiaridades locais, na perspectiva da articulação às estruturas e práticas em comunidades concretas (FREITAS, 2011), como serem expressões do resultado de opções políticas ocorrentes no contexto das relações de poder que se processam nos âmbitos municipais da composição mesorregional, fazendo avançar mais ou menos os referenciais da gestão democrática do ensino público.

No que concerne aos espaços e mecanismos institucionalizados de participação propriamente ditos, o exame das leis permitiu mapear um conjunto de 11 elementos presentes em municípios das diferentes mesorregiões do estado, conforme consta no Quadro 2.

5 Referimo-nos aos princípios de número 2 e 9 do Quadro 1. 
Quadro 2. Espaços e mecanismos de participação constantes nas leis dos sistemas municipais de ensino do estado do Piauí, segundo as mesorregiões geográficas.

\begin{tabular}{|l|c|c|c|c|c|}
\hline \multirow{2}{*}{ Espaços e mecanismos } & \multicolumn{5}{|c|}{ Frequência } \\
\cline { 2 - 7 } & $\begin{array}{c}\text { Norte } \\
\text { Piauiense } \\
\text { (11 leis) }\end{array}$ & $\begin{array}{c}\text { Centro- } \\
\text { Norte } \\
\text { Piauiense } \\
\text { (32 leis) }\end{array}$ & $\begin{array}{c}\text { Sudeste } \\
\text { Piauiense } \\
\text { (23 leis) }\end{array}$ & $\begin{array}{c}\text { Sudoeste } \\
\text { Piauiense } \\
\text { (21 leis) }\end{array}$ & $\begin{array}{c}\text { Total } \\
\text { (87 leis) }\end{array}$ \\
\hline $\begin{array}{l}\text { Conselho Municipal de } \\
\text { Educação }\end{array}$ & 11 & 32 & 23 & 21 & $87(100 \%)$ \\
\hline $\begin{array}{l}\text { Plano Municipal de } \\
\text { Educação }\end{array}$ & 8 & 22 & 17 & 16 & $63(72,4 \%)$ \\
\hline $\begin{array}{l}\text { Projeto Político- } \\
\text { Pedagógico }\end{array}$ & 7 & 14 & 9 & 5 & $35(40,2 \%)$ \\
\hline $\begin{array}{l}\text { Conferência Municipal de } \\
\text { Educação }\end{array}$ & 2 & 11 & 14 & 7 & $34(39,0 \%)$ \\
\hline Conselho Escolar & 2 & 10 & 15 & 6 & $33(37,9 \%)$ \\
\hline $\begin{array}{l}\text { Plano Plurianual de } \\
\text { Educação }\end{array}$ & 2 & 9 & 8 & 3 & $24(27,6 \%)$ \\
\hline $\begin{array}{l}\text { Lei de Diretrizes } \\
\text { Orçamentárias }\end{array}$ & 6 & 6 & 9 & - & $21(24,1 \%)$ \\
\hline Órgãos Colegiados & 1 & 5 & 7 & 5 & $18(20,7 \%)$ \\
\hline Eleição da equipe diretiva & - & - & - & 3 & $3(3,4 \%)$ \\
\hline 10. Grêmios & 2 & 8 & $11(12,6 \%)$ \\
\hline 11. Conselho Fiscal & $23 \%)$ \\
\hline
\end{tabular}

Fonte: Rede Mapa (2016).

Conforme os dados sistematizados no Quadro 2, o Conselho Municipal de Educação ${ }^{6}$ figura como o espaço institucionalizado de participação mais frequente nas leis dos sistemas de ensino dos municípios das quatro mesorregiões, tendo alcançado a totalidade dos documentos. A par desse espaço, ainda que referido em, aproximadamente, $72 \%$ das leis, está o Plano Municipal de Educação, entendido como instrumento de política e gestão da educação.

Importa destacar, também, que a incidência dos demais espaços e mecanismos de participação mapeados estampa um quadro relativamente díspar entre as mesorregiões, conforme se pode verificar na proporção de menções, em relação

\footnotetext{
6 Em linhas gerais, a legislação atribui ao Conselho o caráter de órgão de natureza colegiada, vinculado à Secretaria Municipal de Educação, que desempenha funções consultiva, deliberativa e normativa (em parte da legislação, somam-se as funções fiscalizadora, propositiva, mobilizadora e de controle social), de forma a assegurar a participação da sociedade na gestão da educação municipal.
} 
ao número de leis de cada unidade geográfica, o que inclui princípios já firmados na LDB, a saber: o projeto político-pedagógico e o conselho escolar?.

Se, de um lado, os dados podem sugerir a presença de forças pouco solidárias à bandeira democrática, por outro, é importante reconhecer que os próprios sistemas de ensino têm sido desafiados à constituição e ao aperfeiçoamento de seus espaços e mecanismos de participação; afinal, a participação aqui referida ancora-se em princípios democráticos entendidos não apenas como valor, mas também como processo (BOTLER, 2011).

Ainda que a lei não seja garantia de uma efetiva participação, parece-nos importante admitir que, no estado democrático de direito, sua legitimidade também "advém da aceitação e da construção participativa do conteúdo material da norma" (OLIVEIRA, 2012, p. 294). Nessa direção, pensar em espaços e mecanismos de participação, como os listados no Quadro 2, requer concebê-los como bases institucionais concretas para viabilização do ato de participar (GRACINDO, 2007) e, por extensão, de fazer acontecer a democracia participativa.

\section{Considerações finais}

O estudo permite constatar que a presença dos temas da participação e da autonomia, no conjunto das bases normativas dos recentes sistemas municipais de ensino piauienses, indicia esforços por configurações convergentes com o princípio constitucional da gestão democrática do ensino público. Todavia, conforme evidenciam os dados, quando examinados os subconjuntos municipais representados por cada uma das quatro mesorregiões, esses mesmos temas são marcados por contrastes, seja em termos de fixação de princípios que os mobilizam e de garantia de espaços ou mecanismos institucionalizados para promovê-los, seja em termos de alinhamento entre princípios firmados e condições de materialização.

Se considerarmos o rico processo de luta pela redemocratização que marcou o final dos anos de 1970 e a década de 1980, cuja direção confrontava o ideário neoliberal já em franca propagação em outros países (FRIGOTTO, 2002), e a já não tão recente convocação nacional aos municípios para que, no exercício de sua autonomia político-administrativa, normatizem a gestão democrática do ensino público no âmbito dos seus sistemas de ensino, será forçoso admitir a expressividade de tais contrastes.

\footnotetext{
Especificidades quanto à adoção de critérios de mérito e desempenho e à consulta pública da comunidade escolar, conforme estabelece a meta 19 do PNE 2014-2024 (BRASIL, 2014), não foram pontualmente identificadas associações, até o presente estágio da pesquisa, aos mecanismos e espaços de participação mapeados. Ademais, a massiva maioria das leis municipais é anterior à aprovação do atual PNE.
} 
Posto que as opções políticas e as práticas concretas cotidianas de democratização, no âmbito dos sistemas municipais de ensino, de que são mostras, sem prejuízo de outros, os princípios e as dinâmicas dos espaços e mecanismos de participação identificados neste estudo, também informam a dimensão dos esforços empreendidos na construção de um projeto de democracia social, entendemos que esses contrastes e as razões de fundo que os produzem têm implicações na forma como se processa a vivência, por parte dos atores sociais, do exercício da participação e da tomada de decisão, fundamentais à construção e legitimação do projeto aqui referido.

Assim, o que nos parece estar em causa é a disposição para fazer avançar as condições, visando à participação direta e ativa do cidadão nas arenas de decisão da política e gestão da educação pública, consoante a ideia de democracia participativa. Para tanto, impõem-se qualificarmos o sentido e o significado da participação, pois há vários em disputa na atualidade (GOHN, 2007), considerados o contexto político, o formato institucional, os compromissos firmados e os agentes políticos envolvidos (SILVA, 2003).

De todo modo, tendo em vista que a postura democrática e o sentido público da prática social da educação são alicerces da gestão democrática (GRACINDO, 2007), entendemos que o cotidiano da prática educativa constitui forte aliado do aperfeiçoamento das diretrizes e das condições afeitas a essa perspectiva de gestão no âmbito dos sistemas de ensino. No caso dos municípios com sistemas institucionalizados, o desafio será o de buscar o aperfeiçoamento dos referenciais oficiais, enquanto nos demais, a tarefa nos parece residir na construção desses referenciais, aqui entendida como um ato político e etapa fundamental de um processo que tem no horizonte a democratização da gestão educacional. 


\title{
Regulatory bases and institutional political conditions of democratic management in municipal educational systems in the state of Piauí
}

\begin{abstract}
The aim of this paper is to analyze the regulatory rules and the institutional political conditions on democratic management of the public education within municipal educational systems of the state of Piaui. Resulting from the municipal stage of a research that was done in the country, the empirical delimitation comprehended the cities of Piaui with institutionalized educational systems whose municipal laws were examined. The results show that the most part of the cities do not have educational system and, among the ones that institutionalized it, the general view of principles, spaces and mechanisms of participation is uneven and a little tuned, existing marked differences among the state regions. It concludes to be in cause the interest in advancing to the conditions that take to direct and active participation of the citizens in politics and management of public education.
\end{abstract}

Keywords: Municipal educational system. Democratic management. Public education.

\section{Bases normativas y condiciones político-institucionales de la gestión democrática en sistemas municipales de enseñanza em el estado de Piauí}

\section{Resumen}

El trabajo tiene por objetivo analizar el cuadro normativo y las condiciones politico-institucionales relativos a gestión democrática de la enseñanza pública en el ámbito de los sistemas municipales de enseñanza del estado de Piauí. Resultante de la etapa estadual de una investigación en red de cobertura nacional, la delimitación empírica comprendió las municipalidades piauienses con sistemas de enseñanza institucionalizados, habiendo sido operado el examen de las respectivas leyes municipales. Los resultados evidencian que la mayor parte de las municipalidades no cuentan con sistema de enseñanza y que, entre los que lo institucionalizaran, el cuadro general de principios, espacios y mecanismos de participación es dispar y poco sintonizado, habiendo diferencias acentuadas entre las mesorregiones del estado. Concluye estar en causa la disposición para hacer avanzar las condiciones de refuerzo a la participación directa y activa del ciudadano en la política y gestión de la educación pública.

Palabras claves: Sistemas municipales de enseñanza. Gestión democrática. Educación pública. 


\section{Referências}

ARROYO, M. G. Gestão democrática: recuperar sua radicalidade política. In: CORREA, B. C.; GARCIA, T. O. (Org.). Políticas educacionais e organização do trabalho na escola. São Paulo: Xamã, 2008. p. 39-56.

AVELAR, L. Clientelismo de Estado e política educacional brasileira. Educação \& Sociedade, Campinas, n. 54, p. 34-49, jan. 1996.

BARDIN, L. Análise de conteúdo. Lisboa: Edições 70; [S.l.]: LDA, 2010.

BAUER, M. W. Análise de conteúdo clássica: uma revisão. In: BAUER, M. W.; GASKELL, G. (Ed.). Pesquisa qualitativa com texto, imagem e som: um manual prático. Tradução de Pedrinho A. Guareschi. Petrópolis: Vozes, 2002. p. 189-217.

BOGDAN, R. C.; BIKLEN, S. K. Investigação qualitativa em educação: uma introdução à teoria e aos métodos. Porto: Porto Editora, 1994.

BOTLER, A. M. H. O diálogo como estratégica da gestão escolar participativa. In: GOMES, A. M. (Org.). Políticas públicas e gestão da educação. Campinas: Mercado de Letras, 2011. p. 187-207.

BRASIL. Constituição (1988). Constituição da República Federativa do Brasil, Brasília, DF: Senado, 1988. Disponível em: $<$ http://www.planalto.gov. br/ccivil_03/constituicao/constituicao.htm. Acesso em: 30 jun. 2016.

. Lei ${ }^{\circ}$ 9.394, de 20 de dezembro de 1996. Estabelece as diretrizes e bases da educação nacional. Diário Oficial [da] República Federativa do Brasil, Poder Executivo, Brasília, DF, 21 dez. 1996. Seção 1, p. 27833-27841.

. Parecer CNE/CEB n ${ }^{\circ} 30$, de 12 de setembro de 2000. Solicita pronunciamento, tendo em vista o Parecer CEB 04/2000. Diário Oficial da União, Poder Executivo, Brasília, DF, 6 out. 2000. Seção 1, p. 25.

. Lei $\mathrm{n}^{\circ} 13.005$, de 25 de junho de 2014. Aprova o Plano Nacional de Educação - PNE e dá outras providências. Diário Oficial União, Poder Executivo, Brasília, DF, Edição Extra, n 120-A, 26 jun. 2014. Seção 1, p. 1-8.

. Instituto Brasileiro de Geografia e Estatística (IBGE). Censo demográfico 2010: retratos do Brasil e do Piauí. Brasília, DF: IBGE, 2011. Disponível em: <http://www.ibge.gov.br/home/presidencia/noticias/pdf/ censo_2010_piaui.pdf $>$. Acesso em: 6 set. 2016. 
BUENO, M. S. S. Descentralização e municipalização do ensino em São Paulo: conceitos e preconceitos. In: MARTINS, A. M.; OLIVEIRA, C.; BUENO, M. S. S. (Org.). Descentralização do estado e municipalização do ensino: problemas e perspectivas. Rio de Janeiro: DP\&A, 2004. p. 177-192.

COUTINHO, C. N. A democracia na batalha das ideias e nas lutas políticas do Brasil de hoje. In: FÁVERO, O.; SEMERARO, G. (Org.). Democracia e a construção do público no pensamento educacional brasileiro. Petrópolis: Vozes, 2002. p. 11-39.

CUNHA, E. S. M. Desenho institucional, participação e deliberação democráticas: conexões. CUNHA, E. S. M.; THEODORO, H. D. (Org.). Desenho institucional democracia e participação: conexões teóricas e possibilidades analíticas. Belo Horizonte: D'Plácido, 2014. p. 19-40.

DÍAZ BORDENAVE, J. E. D. O que é participação. São Paulo: Brasiliense, 1985.

FARIA, L. C. M. de; SOUZA, D. B. de. Reforma do Estado, descentralização e municipalização do ensino no Brasil: a gestão política dos sistemas públicos de ensino pós-LDB 9.394/93. Ensaio: Avaliação e Políticas Públicas em Educação, Rio de Janeiro, v. 12, n. 45, p. 925-944, out./dez. 2004.

FLACH, S. F.; SAKATA, K. L. da S. O princípio da gestão democrática na educação pública e sua efetivação no âmbito do sistema municipal de ensino de Ponta Grossa-PR. Revista Brasileira de Política e Administração da Educação, Goiânia, v. 32, n. 2, p. 549-569, maio/ago. 2016.

FREITAS, A. S. de. Gestão social da educação: para além dos paradigmas da administração. In: GOMES, A. M. (Org.). Políticas públicas e gestão da educação. Campinas: Mercado de Letras, 2011. p. 57-83.

FRIGOTTO, G. Educação e a construção democrática no Brasil: da ditadura civil-militar à ditadura do capital. In: FÁVERO, O.; SEMERARO, G. (Org.). Democracia e a construção do público no pensamento educacional brasileiro. Petrópolis: Vozes, 2002. p. 53-67.

GOHN, M. G. Conselhos e colegiados na esfera pública: em busca do sentido. In: CURY, C. R. J.; TOSTA, S. de F. P. Educação, cidade e cidadania: leituras de experiências socioeducativas. Belo Horizonte: PUC Minas; Autêntica, 2007. p. 127-143.

GRACINDO, R. V. Gestão democrática nos sistemas e na escola. Brasília, DF: UnB, 2007. 
IANNI, O. Pensamento social no Brasil. Bauru: EDUSC, 2004.

LIMA, L. A escola como organização educativa. 2. ed. São Paulo: Cortez, 2003.

NOGUEIRA, S. M. A.; RANGEL, J. S. O estado federativo de cooperação e as políticas de municipalização do ensino: limites e potenciais. Ensaio: Avaliação e Políticas Públicas em Educação, Rio de Janeiro, v. 19, n. 72, p. 509-526, jul./set. 2011.

OLIVEIRA, O. S. de et al. Perspectivas na consolidação do sistema de ensino brasileiro: o desenho da democratização proposto nas leis de diretrizes e bases - Leis 4.024/61 e 9.394/96. Jornal de Políticas Educacionais, Curitiba, v. 4, n. 7, p. 41-52, jan./jun. 2010.

OLIVEIRA, F. F. Lei. In: CASTRO, C. L. F. de; AMABILE, A. E. N. de; GONTIJO, C. R. B. (Org.). Dicionário de políticas públicas. Barbacena: EdUEMG, 2012. p. 294-295.

PANIS, L. M.; NARDI, E. L. Implementação de Sistemas Municipais de Ensino: entre condições locais e expectativas de desenvolvimento educacional. Educação: Teoria e Prática, Rio Claro, v. 24, n. 47, p. 156-175, set./dez. 2014.

PARO, V. H. Administração escolar: introdução crítica. São Paulo: Cortez, 1986.

PAZ, V. O. O município e a organização da educação: caminhos e desafios da criação e implantação do sistema municipal de ensino de AnanindeuaPA. 2009. 207 f. Dissertação (Mestrado em Educação) - Programa de Pós-Graduação em Educação, Instituto de Ciências da Educação, Universidade Federal do Pará, Belém, 2009.

. Institucionalização da gestão democrática da educação como política pública no sistema municipal de ensino de Igarapé-Açu, Pará. 2015. 228 f. Tese (Doutorado em Educação) - Programa de Pós-Graduação em Educação, Instituto de Ciências da Educação, Universidade Federal do Pará, Belém, 2015.

PEREIRA, M. S. V. A institucionalização dos sistemas municipais de ensino na realidade paraense: obstáculos e possibilidades: o caso do município de Barcarena. 2010. 191 f. Dissertação (Mestrado em Educação) - Programa de Pós-Graduação em Educação, Instituto de Ciências da Educação, Universidade Federal do Pará, Belém, 2010. 
PIAUÍ. Lei n 5.101 de 23 de novembro de 1999. Dispõe sobre o sistema de ensino do Estado e dá outras providências. Diário Oficial do Estado do Piauí, Piauí, 25 nov. 1999. Disponível em: <http://servleg.al.pi.gov.br:9080/ALEPI/sapl_ documentos/norma_juridica/1812_texto_integral>. Acesso em: 10 mar. 2016.

. Parecer CEE/PI n ${ }^{\circ}$ 054, de 03 de dezembro de 2004. Orienta os municípios do Piaui sobre a organização de seus Sistemas de Ensino e dá outras providências. Teresina: Conselho Estadual de Educação, 2004.

REDE MAPA. Gestão democrática do ensino público: mapeamento das bases normativas e das condições político-institucionais dos sistemas municipais de ensino. Legislação municipal. Subprojeto Piauí, 2016.

. Gestão democrática do ensino público: mapeamento das bases normativas e das condições político-institucionais dos sistemas municipais de ensino. Dados preliminares da etapa documental. Subprojetos estaduais, 2017.

ROMÃO, J. E. Sistemas municipais de educação: a Lei de Diretrizes e Bases e a educação no município. São Paulo: Ed. Instituto Paulo Freire, 2010.

SARMENTO, D. C. Criação dos sistemas municipais de ensino. Educação \& Sociedade. Campinas, v. 26, n. 93, p. 1363-1390, set./dez. 2005.

SILVA, I. G. Democracia e participação na reforma do Estado. São Paulo: Cortez, 2003.

SOUZA, D. B.; CASTRO, D. F. Gestão democrática da educação sob perspectiva comparada Brasil-Portugal: entre a exigência legal e a exequibilidade real. Educação \& Sociedade, Campinas, v. 33, n. 121, p. 1195-1213, out./dez. 2012.

STÜRNER, A. B. Democracia e participação na escola pública. Revista Eletrônica de Educação, São Carlos, v. 5, n. 2, p. 124-135, nov. 2011.

TEODORO, A. Organizações internacionais e políticas educativas nacionais: a emergência de novas formas de regulação transnacional, ou uma globalização de baixa intensidade. In: STOER, S. R.; CORTESÃO, L.; CORREIA, J. A. (Org.). Transnacionalização da educação: da crise da educação à "educação" da crise. Porto: Afrontamento, 2001. p. 125-161.

TERESINA. Lei $\mathrm{n}^{\circ} 1.802$, de 30 de novembro de 1984. Regula a indicação dos dirigentes e vice-diretores da Rede Municipal de Ensino. Diário Oficial do Município, Teresina 1984. 
TERESINA. Lei ${ }^{\circ} 2.900$, de 14 de abril de 2000. Institui o sistema municipal de Teresina e dá outras providências. Diário Oficial do Município, Teresina, 28 abr. 2000. Disponível em: <http://www.teresina.pi.leg.br/acervodigital/ norma/lei-2900-2000>. Acesso em: 20 maio 2016.

WERLE, F. O. C.; THUM, A. B.; ANDRADE, A. C. de. Processo nacional de avaliação do rendimento escolar: tema esquecido entre os Sistemas Municipais de Ensino. Ensaio: Avaliação e Políticas Públicas em Educação, Rio de Janeiro, v. 17, n. 64, p. 397-420, jul./set. 2009.

\section{Informações dos autores}

Raimunda Maria da Cunha Ribeiro: Doutora em Educação pela Pontifícia Universidade Católica do Rio Grande do Sul (PUCRS). Professora da Universidade Estadual do Piauí (Uespi). Contato: raicribeiro@ig.com.br

EIton Luiz Nardi: Doutor em Educação pela Universidade do Vale do Rio dos Sinos (Unisinos). Professor do Programa de Pós-Graduação em Educação da Universidade do Oeste de Santa Catarina (Unoesc). Contato: elton.nardi@unoesc.edu.br 